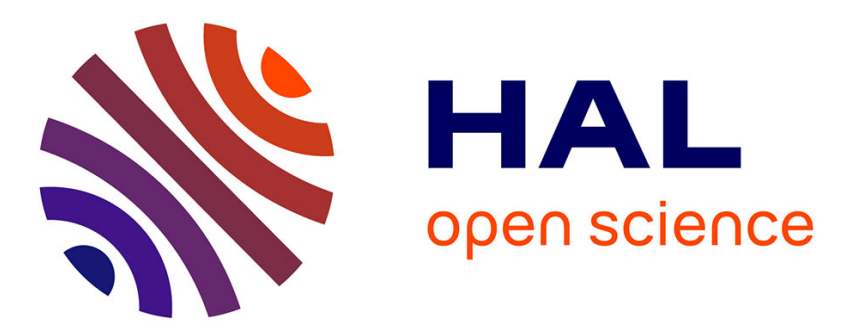

\title{
Faster speed at the expense of arm-trunk coordination during reaching in chronic spastic stroke patients
}

Laurence Mandon, Julien Boudarham, Johanna Robertson, Djamel Bensmail, Nicolas Roche, Agnès Roby-Brami

\section{- To cite this version:}

Laurence Mandon, Julien Boudarham, Johanna Robertson, Djamel Bensmail, Nicolas Roche, et al.. Faster speed at the expense of arm-trunk coordination during reaching in chronic spastic stroke patients. Neurorehabilitation and Neural Repair, 2016, 30 (3), pp.209-220. 10.1177/1545968315591704 . hal-01289428

\section{HAL Id: hal-01289428 https://hal.sorbonne-universite.fr/hal-01289428}

Submitted on 16 Mar 2016

HAL is a multi-disciplinary open access archive for the deposit and dissemination of scientific research documents, whether they are published or not. The documents may come from teaching and research institutions in France or abroad, or from public or private research centers.
L'archive ouverte pluridisciplinaire $\mathbf{H A L}$, est destinée au dépôt et à la diffusion de documents scientifiques de niveau recherche, publiés ou non, émanant des établissements d'enseignement et de recherche français ou étrangers, des laboratoires publics ou privés. 
Faster speed for reaching.

\section{Faster speed at the expense of arm-trunk coordination during reaching in chronic spastic stroke patients.}

Laurence Mandon $\mathrm{MD}^{1,2}$, Julien Boudarham $\mathrm{PhD}^{2}$, Johanna Robertson PT $\mathrm{PhD}^{1,2}$, Djamel Bensmail MD $\mathrm{PhD}^{1,2}$, Nicolas Roche MD PhD ${ }^{1,2}$, Agnès RobyBrami MD $\mathrm{PhD}^{2,3,4,5}$.

1: Department of Physical medicine and Rehabilitation, Raymond Poincaré Hospital, Garches, 92780, France

2: GRCTH, EA4497, CIC-IT 805, CHU Raymond Poincaré, UVSQ, Garches, 92780, France.

3: CNRS, UMR 7222, ISIR, F-75005 Paris, France

4: Sorbonne Universités, UPMC Univ Paris 06, UMR 7222, F-75005 Paris, France

5: INSERM, U1150, Agathe-ISIR, F-75005 Paris, France

\section{Corresponding author:}

Agnes Roby-Brami

Tél +33(0)144276215

Fax $+33(0) 144275145$

roby-brami@isir.upmc.fr 
Faster speed for reaching.

Running title: Faster speed for reaching.

Number of words: 4550 words

\section{Figures and Tables:}

Figure 1: Effect of speed condition on hand kinematics.

Figure 2: Effect of speed condition on elbow extension and trunk displacement.

Figure 3: Scaling of elbow extension in individual patients.

Figure 4. Contribution of trunk displacement and upper-limb lengthening to reach distance in individual patients.

Table 1: Patients characteristics.

Table 2: Clinical assessment of the patients.

$-2-$ 
Faster speed for reaching.

\begin{abstract}
(247 words)
Background: The velocity of reaching movements is often reduced in patients with strokerelated hemiparesis, however they are able to voluntarily increase paretic hand velocity. Previous studies have proposed that faster speed improves movement quality.
\end{abstract}

Objective: To investigate the combined effects of reaching distance and speed instruction on trunk and paretic upper-limb coordination. The hypothesis was that increased speed would reduce elbow extension and increase compensatory trunk flexion.

Methods: A single session study in which reaching kinematics were recorded in a group of 14 patients with spastic hemiparesis. A 3D-motion analysis system was used to track the trajectories of 5 reflective markers fixed on the finger, wrist, elbow, acromion and sternum. The reaching movements were performed to two targets at respectively $60 \%$ and $90 \%$ arm length, at preferred and maximum velocity. The experiment was repeated with the trunk restrained by a strap.

Results: All the patients were able to voluntarily increase reaching velocity. In the trunk free, faster speed condition, elbow extension velocity increased but elbow extension amplitude decreased and trunk motion increased. In the trunk restraint condition, elbow extension amplitude did not decrease with faster speed. Seven patients scaled elbow extension and elbow extension velocity as a function of reach distance, the other 7 mainly increased trunk compensation with increased task constraints. There were no clear clinical characteristics that could explain this difference.

Conclusions: Faster speed may encourage some patients to use compensation. Individual indications for therapy could be based on a quantitative analysis of reaching coordination. Keywords : kinematics, hemiparesis, coordination, elbow, trunk 
Faster speed for reaching.

\section{Introduction}

Impairment of upper-limb motor control is a major cause of disability in patients with stroke-induced cerebral lesions. It is well known that reaching and grasping movements in hemiparetic patients are slow and segmented ${ }^{1}$ but the mechanisms which cause the slowness are still unclear. Movement slowness may be the direct consequence of the weakness which occurs after a brain lesion ${ }^{2,3}$. The impairment of coordination due to the lack of cortico-spinal control likely also contributes through loss of individual joint control ${ }^{4}$, agonist-antagonist muscle coordination ${ }^{5}$ and inter-joint coordination ${ }^{6}$. Slowness and lack of smoothness can also be due to impairment of the temporal blending of sub-movements, leading to segmented and irregular trajectories ${ }^{7}$. In addition, positive symptoms with excessive muscle contractions such as spasticity ${ }^{8,9}$, spastic co-contraction ${ }^{10}$ and pathological synergies ${ }^{11}$ ) have all been suggested to potentially slow movement.

Recently, several studies demonstrated that hemiparetic patients were able to perform faster movements when required to do so and that a faster speed of execution improved movement smoothness ${ }^{12-15}$. However, the impact of faster speed instruction on movement extent and coordination has not yet been investigated. Voluntary increases in reach velocity may influence movement execution across joints and may also lead to inappropriate muscle activity in hemiparetic patients.

Gotlieb and co-workers examined the regulation of movement velocity in a single joint in healthy subjects. They investigated elbow movements in the horizontal plane and proposed that velocity varied according to a pulse-step model of the activation sent to the agonist motoneurons. Changes in velocity according to target distance (which are not voluntary) could be explained by the duration of the pulse (pulse width) ${ }^{16}$.This "speed insensitive strategy" may be the default mode ${ }^{17}$. In contrast, when the velocity is related to an explicit speed instruction (speed sensitive strategy), it is modulated by the intensity of the excitatory 
Faster speed for reaching.

pulses (pulse height). Pulse height and pulse width can be modulated independently in a variety of single joint tasks ${ }^{18-20}$, as well as during planar two-joint movements in healthy subjects ${ }^{21}$. The regulation of movement extent according to the principle of pulse height and pulse width has also been demonstrated in hemiparetic patients ${ }^{22}$.

In hemiparetic patients, the control of the velocity of a single joint is complicated by spasticity-related inappropriate muscle activity which can limit range of motion ${ }^{8}$. Recent studies have demonstrated that spasticity is characterized by a decrease in the stretch reflex (SR) threshold that occurred within the anatomical limits of joint motion ${ }^{5,23}$. Thus, the slow stretching of muscles beyond the static reflex threshold triggers a contraction of the muscle, limiting movement. When the muscle is stretched faster, the threshold of activation is progressively reduced, further limiting range of motion ${ }^{5,24}$. It is generally agreed that spasticity contributes to the slowing of active reaching movements but this has not been clearly demonstrated ${ }^{25-29}$. More generally, the relationships between force, active range of motion and spasticity are still debated ${ }^{4,30}$ although it has been proposed that, in spastic hemiparesis, all motor impairments could result from limitations in the central specification of SR thresholds 5,31 .

During unconstrained multi-joint reaching movements, hemiparetic patients generally use the redundancy of the body, increasing trunk flexion in order to compensate for the impairment of elbow extension ${ }^{32,33}$. Trunk flexion increases reachable distance in both healthy subjects and hemiparetic patients. When reaching to distant targets, trunk flexion occurs earlier and is of greater amplitude in hemiparetic patients than in healthy subjects, suggesting that it is triggered at a lower threshold of elbow extension ${ }^{34}$. In addition, the involvement of the trunk increases the velocity of the hand ${ }^{35}$. However, it has been shown that patients are actually able to increase range of motion in the shoulder and elbow and use better coordination to reach a distant target when trunk flexion is blocked by a restraining belt $-5-$ 
Faster speed for reaching.

${ }^{36}$. This suggests that the patients spontaneously use trunk compensation, rather than using their full potential of upper limb motion, probably to reduce effort.

The aim of the present study was to analyze the impact of increased reaching speed condition on both hand kinematics and arm-trunk coordination in patients with stroke-related hemiplegia. The first aim was to investigate the combined effects of reaching distance and speed condition on the coordination of trunk and paretic upper-limb motion. The working hypothesis was that range of elbow extension motion and/or velocity would be limited by the loss of motor control and/or inappropriate muscle activity and that patients would thus increase trunk motion in order to achieve a faster reach. The analysis focused on elbow extension (indicative of the quality of arm motion ${ }^{32,37}$ ) and trunk displacement (indicative of a compensatory strategy ${ }^{38}$ ). The second aim was to investigate the ability of the patients to perform faster reaching movements when the trunk was restrained. ${ }^{32-34,39}$. The working hypothesis was that trunk restraint would reveal the limits of the patients' capacity to adapt reaching movements to more difficult (increased distance and/or speed) conditions.

The overall aim of this single session study was to test the hypothesis that faster speed would favor the use of unsuitable compensatory motor behavior. This is clinically relevant since recent neuro-rehabilitation methods based on motor learning principles ${ }^{40-44}$ may favor the use of faster speed instructions as a general means to increase the intensity of therapy ${ }^{12}$.

$-6-$ 
Faster speed for reaching.

\section{Methods}

\section{Subjects and clinical evaluation}

The study was approved by the local Institutional Review Board. Fourteen hemiparetic patients were included following signing of the informed consent form. They had all sustained a single unilateral stroke of non-traumatic origin at least one year previously (Table 1). All exhibited spasticity of the paretic arm and were included in a program of regular Botulinum toxin injections (the recordings were made at least twelve weeks after the last injection, when the activity of the Botulinum toxin had ceased ${ }^{45}$. Patients with hemispatial neglect, apraxia or shoulder pain or other neurological or orthopedic conditions affecting the arm or trunk were excluded. Patients had to understand simple instructions. The clinical assessment included : the arm section of the Fugl-Meyer Scale (Maximum score 66) which is a reliable and valid test for the assessment of arm and hand impairment in stroke patients ${ }^{46}$; the Action Research Arm Test (ARAT) which scores the capacity to grasp and manipulate different sized objects (maximum score 57) and is reliable, valid and sensitive ${ }^{47}$ and the Motor Activity Log (MAL) which is a semi-structured interview for the assessment of frequency of use and quality of use of the affected limb in daily life. This test is a reliable and valid tool for the measurement of arm and hand activity ${ }^{48}$.

Spasticity of the paretic elbow flexors was rated using the modified Ashworth Scale. Passive range of motion of the main paretic upper limb joints was measured using a manual goniometer and strength of the main upper limb muscle groups was evaluated using the MRC scale.

\section{Reaching Task}

Participants were seated in a chair with their hand placed on the table in line with the shoulder (elbow approximately at $90^{\circ}$ ). The starting position was marked for each patient. The task was to reach forward with the paretic hand to touch a target (colored spot, $1 \mathrm{~cm}$

$$
-7-
$$


Faster speed for reaching.

diameter) placed on a table in the mid-sagittal plane at $60 \%$ and $90 \%$ of the his/her nonparetic arm length (measured from the acromion process to the mid-palmar crease). The instruction was to touch the target with the ulnar border of the hand formed as a fist and then return to the initial position. This task was chosen so that it would be possible even for patients with severe impairment, and was independent of hand and finger function. Two speed conditions were assessed: preferred speed (patients' spontaneous speed) and fast speed (patients were instructed to reach 'as fast as possible'). The order of the tasks was not randomized: the easiest conditions were performed first in order to record the most "spontaneous" behavior and to avoid excessive fatigue. Throughout the text the word "speed" is used to specify the condition and the word "velocity" refers to the measured movement.

The trails were performed initially with the trunk free (trunk free condition) and were then repeated with the trunk restrained (trunk restrained condition) by a large strap across the chest.

Five trials were recorded for each of the eight conditions: target distance (close and far) $\mathrm{x}$ speed condition (preferred and fast) $\mathrm{x}$ trunk (free and restrained).

\section{Data recording and analysis}

Movement kinematics were recorded using 8 optoelectronic cameras (Motion Analysis Corporation, sampling frequency $100 \mathrm{~Hz}$ ) which measured the three-dimensional coordinates of 5 reflective markers positioned on the proximal inter-phalangeal joint of the index finger, the radial styloid process of the wrist (RS), the lateral epicondyle of the humerus (LE), the acromion processes (AC) and the upper part of the sternum (ST) ${ }^{34}$. The experimenter triggered the recording then asked the patient to perform the movement.

All data were processed using customized algorithms developed using Labview 8.5 (National Instruments). The data analysis focused on three types of movement variables: kinematics of the hand in space (measured using the RS marker since the finger marker was $-8-$ 
Faster speed for reaching.

not always exploitable), and amplitude of elbow joint rotations, arm length and trunk displacements.

Position data were filtered (low-pass cutoff, $20 \mathrm{~Hz}$ ) plotted in 3D and the tangential velocity profile of the RS marker was computed. The reach was analyzed from the initial to the final hand position on (or near) the target. The onset and offset times of the reaching movement, were automatically determined for each trial (with a threshold of $0.05 \mathrm{~m} / \mathrm{s}$ ) and then visually checked. Peak velocity, reach duration (difference between onset and offset times) and reach distance (3D distance covered by the RS marker) were calculated. A curvature index was computed as the ratio between total end point path length and a straight line joining the initial and final positions ${ }^{49}$. Trajectory smoothness was calculated as the number of velocity peaks (greater than one tenth of peak velocity and longer than $90 \mathrm{~ms}$ ).

Elbow angle was computed using vectors which respectively joined the $\mathrm{AC}$ and LE markers and the LE and RS markers. The amplitude of extension during the reach and the maximum velocity of elbow rotation were calculated. The 3D displacements of the ST and AC markers were computed to estimate the respective contribution of trunk flexion and trunk axial rotation. Functional arm length was calculated as the 3D distance between the SR and AC bony landmarks.

All movement trials were considered, whether or not the patients reached the target. Statistical analysis was performed on the mean of the 3-5 trials recorded in each condition for each participant (some trials had to be excluded due to technical problems, mostly hidden markers). A non parametric Friedman test was used to test the effect between the conditions (eight different conditions) and then a Wilcoxon test was used for paired comparisons. The significance level of the Wilcoxon test was set at $\mathrm{p}<0.006$ following Bonferroni correction for 8 comparisons. A Mann Whitney test was used to analyze differences between subgroups of patients. Regression analysis was performed with reach distance (3D displacement of the SR 
Faster speed for reaching.

marker) as the independent variable and elbow extension and 3D displacement of the AC marker as dependant variables.

Tables with further data and supplementary figures will be available on the web page of an author (http://people.isir.upmc.fr/roby-brami).

\section{Results}

The results of the clinical evaluation are presented in Table 2.

\section{Effect of speed condition on hand kinematics.}

All the patients were able to carry out the reaching movements in the different experimental conditions, although they did not always reach the target.

Variables relating to the end point kinematics are presented in Figure 1. The Friedman test showed that all the variables varied with the conditions, the stars on Figure 1 indicate significant paired differences between conditions (Wilcoxon test).

The most spontaneous motor behavior was performed with the trunk free at preferred speed. In this condition, reach distance was $0.216 \pm 0.017 \mathrm{~m}$ (mean \pm sem) for the far target and $0.120 \pm 0.006 \mathrm{~m}$ for the close target (Figure 1A). Peak velocity varied with reach distance since it was greater (not significantly) for the far target $(0.40 \pm 0.05 \mathrm{~m} / \mathrm{s})$ than for the close target $(0.33 \pm 0.03 \mathrm{~m} / \mathrm{s}$, Figure 1B, see supplementary table $\mathrm{S} 1$ for individual data). Reach duration was not significantly different between targets $(2.03 \pm 0.36$ and $1.67 \mathrm{~s} \pm 0.22 \mathrm{~s}$ for the far and close targets respectively, Figure 1C). Peak count did not vary with target distance (Figure 1D).

In the fast condition, peak velocity increased and duration decreased significantly compared with the preferred speed condition. The reach distance was not significantly different than in the preferred speed condition. There was a significant effect of target in the fast condition: peak velocity was greater for the far $(0.68 \pm 0.04 \mathrm{~m} / \mathrm{s})$ than for the close target 
Faster speed for reaching.

$(0.52 \pm 0.04 \mathrm{~m} / \mathrm{s})$. Reach duration was slightly but not significantly longer for the far $(0.95 \pm$ $0.12 \mathrm{~s})$ than for the close target $(0.78 \pm 0.76 \mathrm{~s})$. Peak count was significantly lower in the fast condition than in the preferred speed condition.

The effect of the trunk restraint is illustrated in the right-hand sections of Figure 1A-D. Reach distance was not significantly modified by the trunk restraint but tended to decrease for the far target-fast speed condition. Peak velocity was not significantly modified by the trunk restraint compared with the trunk free conditions and varied in a similar way with target and instruction. Reach duration increased with target distance, but the mean values were not significantly different than the trunk free condition. The variations of the peak count were similar in trunk free and restraint conditions.

The curvature index varied little with the condition, except that in the fast conditions it was greater for the close than the far target $(\mathrm{p}<0.05)$.

To summarize, endpoint kinematics were modulated by target distance and speed condition but were little affected by trunk restraint.

\section{Effect of speed condition on trunk contribution to the reaching movement.}

The contribution of the trunk to the reaching movement is shown by the $3 \mathrm{D}$ displacement of the ST marker (which relates to trunk flexion) and that of the AC marker (which relates to trunk flexion and axial rotation) (Figure 2A-B). In the trunk free- preferred speed condition, the trunk contribution was relatively small for the close target $(0.04 \pm 0.01 \mathrm{~m}$ and $0.07 \pm$ $0.01 \mathrm{~m}$ for ST and AC respectively) and increased significantly with target distance (to reach $0.08 \pm 0.01 \mathrm{~m}$ and $0.12 \pm 0.02 \mathrm{~m}$ for the far target for ST and AC respectively). In the trunk free-fast speed condition, trunk motion was greater than in the preferred speed condition reaching $0.10 \pm 0.02 \mathrm{~m}$ and $0.16 \pm 0.02 \mathrm{~m}$ for the far target (ST and AC respectively). The difference between speed conditions was significant for the far but not the close target.

$-11-$ 
Faster speed for reaching.

In the trunk restraint condition, the strap limited, but did not completely prevent trunk displacement. ST displacement was always less than $0.05 \mathrm{~m}$ even for the far target, but AC displacement increased with target distance $(0.04 \pm 0.01 \mathrm{~m}$ and $0.09 \pm 0.01 \mathrm{~m}$ for the close and far targets). In the fast condition, ST displacement did not change, but AC displacement increased for the close but not for the far target. This suggests that the physical limit of the strap allowed a maximum displacement of $0.05 \mathrm{~m}$ for ST and $0.09 \mathrm{~m}$ for AC, probably because trunk torsion was less blocked than flexion.

\section{Effect of speed condition on elbow extension.}

In the trunk free condition, elbow extension (Figure 2C) increased significantly with target distance $\left(10.2 \pm 2.0^{\circ}\right.$ and $18.8 \pm 4^{\circ}$ respectively for the close and far targets). Maximal elbow extension was less in the fast compared with the preferred speed condition and was scaled to reach distance $\left(7.5 \pm 2.1^{\circ}\right.$ and $12.9 \pm 3.6^{\circ}$ respectively for the close and far targets $)$. The difference between the preferred and fast speed conditions was significant for the far but not the close target. Elbow extension velocity (Figure 2D) increased significantly in the fast condition. Extension velocity was scaled to target distance in the fast $\left(58.0 \pm 7.3^{\circ}\right.$ and $76.2 \pm$ $9.7^{\circ}$ respectively for the close and far targets) but not in the preferred speed condition $(33.5 \pm$ $3 \% \mathrm{~s}$ and $45.9 \pm 8 \% \mathrm{~s}$ for the close and far targets).

Trunk restraint increased elbow extension compared to the trunk free condition, (significantly for the far but not the close target). In the trunk restraint condition, maximal elbow extension was significantly scaled to target distance and was significantly lower in the fast than in the preferred speed condition (close preferred $13.7 \pm 2.1^{\circ}$; far preferred $26.9 \pm$ $4.1^{\circ}$; close fast $10.3 \pm 2.1^{\circ}$; far fast $21.7 \pm 4.1^{\circ}$ ). Elbow extension velocity was not significantly greater in the trunk restraint than in the trunk free condition and there was no significant difference between the fast and preferred speed conditions. 
Faster speed for reaching.

Individual analysis of the scaling of elbow extension and AC displacement to reach distance.

Regression analysis was used to investigate the relationship between elbow extension and reach distance for each participant (Figure 3 A-B, see supplementary Table S2). The regression analysis was significant in most cases. In seven patients, it was significant in all four trunk and speed conditions (r2 0.612 to 0.995 ); in the seven others it was not always significant (or was significantly towards flexion in one patient), see supplementary Table S2.

The individual values of elbow extension and elbow extension velocity are shown in Figure $3 \mathrm{C}$. The patients are ranked according to their ability to scale elbow extension to movement distance. The first seven patients who regularly scaled elbow extension to movement distance were able to increase the velocity of elbow extension when the instruction was to go faster. This was not the case for the seven other patients. Elbow extension velocity was significantly different between these two sub-groups (Mann-Whitney, $\mathrm{p}<0.0001$ ).

The amount of AC displacement increased significantly with reach distance (see supplementary Figure S1 and Table S3). In the trunk free condition, the slope of this relationship varied between 0.28 and 1.08 in the preferred speed condition and between 0.15 and 1.4 in the fast condition (a slope of 1 indicates that hand displacement is entirely the result of trunk displacement). In the trunk fixed condition, the amount of AC displacement was also significantly related to reach distance in most patients, despite the strap. The slope of this relationship varied between 0.17 and 0.9 in the preferred speed condition and between 0.24 and 0.97 in the fast condition.

\section{Coordination between the trunk and upper-limb.}

The reach distance is ensured by the added contribution of the lengthening of the arm (increase in the distance between SR and AC) and AC displacement (see supplementary Figure S2). The relative contributions of the trunk and upper limb for each individual are illustrated in Figure 4 in the trunk free condition. The direction of the vectors indicates the 
Faster speed for reaching.

difference between preferred and fast speed conditions. Figure 4 shows that fast speed associates an increase in $\mathrm{AC}$ displacement corresponding, with a few exceptions, to a decrease of arm lengthening. In four cases, the effort required to make faster reaches resulted in a decrease rather than an increase of arm length.

Comparison with clinical data.

The individual patients in Tables 1 and 2 are presented in the same order as in Figure 3C. The analysis of individual results and the comparison of clinical and kinematic data did not show clear cut clinical differences between the patients who were able or not to scale elbow extension to movement distance. For example, the Fugl Meyer scores were 25-53 versus 1146 respectively. However, it is noteworthy that the patients with the most severe spasticity (MAS 3) were among the least able to regulate elbow extension to target distance.

\section{Discussion}

In healthy subjects, it is well known that hand velocity increases with target distance ${ }^{50}$ and with the instruction to move faster. As suggested by Gottlieb, these factors correspond to independent organizing principles respectively called speed insensitive ${ }^{16}$ and speed sensitive strategies ${ }^{51}$. The present study confirms that hemiparetic patients are able to voluntarily increase movement velocity ${ }^{12-15}$. The effect of target distance was significant in the fast condition but not in the preferred speed condition, in contrast with the results of several previous studies ${ }^{22,35,52}$ which showed that hand velocity increased with movement distance in hemiparetic patients.

Faster movements were also smoother as shown by a lower number of peaks ${ }^{53}$.

The main result of the present study was that faster hand velocity affects arm-trunk coordination, in contrast with what had previously been claimed ${ }^{13}$.

Due to the large redundancy of the body and limb segments ${ }^{54}$, hand movement can be generated by infinity of arm and trunk coordination. The present observations in the preferred 
Faster speed for reaching.

speed condition confirmed that hemiparetic stroke patients take advantage of this redundancy and use greater trunk flexion ${ }^{33-35}$ and rotation ${ }^{39}$ to compensate for the impairment of elbow extension. Both trunk movements and elbow extension were scaled to reach distance ${ }^{34}$. The present study also confirmed that when the participation of the trunk was limited by a restraining strap, the patients were able to increase elbow extension amplitude so that the extent of the hand movement was not altered ${ }^{36}$.

The voluntary increase in movement velocity had twofold consequences. On the one hand, the patients were able to increase elbow extension velocity and to scale it to movement distance, which is consistent with the observation of single joint planar movements in healthy subjects ${ }^{16,51,55,56}$. On the other hand, the faster movement strongly impacted arm-trunk coordination. Firstly, the increase in elbow extension velocity was performed at the expense of elbow extension amplitude which was consistently decreased. Secondly, trunk compensation increased consistently: this was observed both when the trunk was free and also, within the limits of the strap, in the restraint condition. Thirdly, the instruction to go faster altered the relative contribution of the trunk and upper-limb to the distance reached: in most patients, the trunk displacement became the main (or even the only) source of hand displacement for reaching. The individual analysis showed that the patients who were able to increase elbow extension when the target distance was increased were also able to increase the velocity of elbow extension when the instruction was to go faster. In contrast, the other patients relied mainly on the trunk to adapt to harder task constraints: increased target distance or faster speed. Unfortunately, the role of trunk participation on the reaching movement was not completely demonstrated since the trunk restraint was not tight enough. It is likely that a complete trunk restraint would have reduced movement extent in the far targetfast speed condition.

$-15-$ 
Faster speed for reaching.

The alteration of arm-trunk coordination with increased reaching speed contrasts with the stability of extension range ${ }^{51,55,56}$ and arm coordination ${ }^{57-60}$ generally reported in healthy subjects, although a recent study demonstrated small differences ${ }^{61}$.

The reduction in elbow extension amplitude with increased reaching speed may be due to spasticity, defined as a velocity dependent increase in the stretch reflex ${ }^{8}$. The patients recruited in this study had different degrees of spasticity. The analysis of individual data did not evidence clear relationships between the clinical and kinematic data except that three of the seven patients with the most severe limitation of elbow extension also had severe spasticity. The velocity of elbow extension observed in the present study was low, less than $85 \%$, which is well below the maximum voluntary velocity observed in healthy subjects during horizontal planar movements (500 to $700 \%$ s) ${ }^{62,63}$ and reaching movements (100$180 \%$ s $)^{64}$. Experiments involving passive stretching of the wrist and elbow flexors in patients with spasticity demonstrated that less than $100 \%$ s velocities could trigger a spastic response $5,31,65$. The relative reduction in elbow range of motion at faster speed could be due to the triggering of a spastic reflex resulting from the impaired regulation of stretch reflex threshold ${ }^{5}$ however, the weakness caused by the lesions of the cortico-spinal pathway may also be involved. Muscle hypo-extensibility probably also contributes to the reduction in elbow extension but cannot explain the further reduction with increased movement velocity. This is more likely to be due to spastic co-contractions ${ }^{10}$ which increase with effort and may induce a reversal of the torque produced at the joint ${ }^{66}$. The main limitation of the present study is that it lacks EMG data that could demonstrate this point.

The alteration of arm-trunk coordination observed in the present study contradicts the previous conclusions that "movement quality improves" with faster task performance ${ }^{12,13,15}$. Previous studies were based on different tasks and analyzes. During reach to grasp movements, increasing movement speed lead to a straighter movement path and larger finger 
Faster speed for reaching.

aperture $^{12,13,15}$ (however, elbow joint rotation and trunk displacements were not measured). Another study involving alternating cyclical movements showed that both elbow extension and trunk displacement were reduced at faster speeds ${ }^{13}$. In addition, all previous studies were carried out in patients with a higher level of function (ARAT scores of 20-53 ${ }^{12}$ or active wrist and finger extension ${ }^{4}$ ) and no or little spasticity. In the present study, the patients were more impaired, had higher levels of spasticity and some were not able to grasp.

\section{Limitations.}

Further studies are needed to confirm the immediate effect of the faster speed condition. The main limitation of this study is that fatigue may have influenced the results since the order of the conditions was not randomized. Another limitation is that because of technical problems, the precision of the reaches was not measured. In addition, the lack of EMG data is a strong limitation for a better understanding of the mechanisms limiting elbow extension velocity.

\section{Conclusion and perspectives.}

The present results demonstrate that faster movement speed incites patients to use a motor schema involving of compensation ${ }^{38}$ rather than faster elbow extension. Compensation may help patients to perform tasks in the short term, but is associated with long term problems ${ }^{67}$ and can lead to a pattern of learned nonuse, limiting subsequent recovery ${ }^{68,69}$. Although it is speculative to infer a possible evolution from a single session study, the present study suggests that training at faster speeds should be used with caution in order to avoid the risk of imposing useless or potentially harmful therapy. The quantitative analysis of reaching coordination presented in the present study could be used to select patients before entering into intensive therapy. Training at faster speeds should be carefully reserved for patients who are able to spontaneously modulate the range and velocity of elbow extension as a function of target distance. It may be contraindicated (or used with caution) in patients who do not 
Faster speed for reaching.

spontaneously scale elbow extension but instead use increased trunk compensation. Trunk restraint, which is already recommended for training elbow extension ${ }^{70,71}$ is particularly recommended if a fast speed training protocol is envisaged. Finally, similar studies are now required on the combined effects of target distance and speed instruction on the trunk and upper-limb reaching coordination during and after a rehabilitation intervention involving fast and/or intense therapy such as robotic interventions ${ }^{40,43,44}$.

$-18-$ 
Faster speed for reaching.

\section{Acknowledgments}

The authors are grateful to the patients who participated in the study. L. Mandon was

supported by SOFMER (Société Française de médecine physique et réadaptation).

\section{Conflict(s)-of-Interest/Disclosure(s)}

None 
Faster speed for reaching.

\section{References}

1. Trombly CA. Observations of improvement of reaching in five subjects with left hemiparesis. J Neurol Neurosurg Psychiatry. Jan 1993;56(1):40-45.

2. Colebatch JG, Gandevia SC. The distribution of muscular weakness in upper motor neuron lesions affecting the arm. Brain. Jun 1989;112:749-763.

3. Sukal-Moulton T, Krosschell KJ, Gaebler-Spira DJ, Dewald JP. Motor impairment factors related to brain injury timing in early hemiparesis. Part I: expression of upperextremity weakness. Neurorehabil Neural Repair. Jan 2014;28(1):13-23.

4. Zackowski KM, Dromerick AW, Sahrmann SA, Thach WT, Bastian AJ. How do strength, sensation, spasticity and joint individuation relate to the reaching deficits of people with chronic hemiparesis? Brain. May 2004;127(Pt 5):1035-1046.

5. Levin MF, Selles RW, Verheul MH, Meijer OG. Deficits in the coordination of agonist and antagonist muscles in stroke patients: implications for normal motor control. Brain Res. Jan 24 2000;853(2):352-369.

6. Levin MF. Interjoint coordination during pointing movements is disrupted in spastic hemiparesis. Brain. Feb 1996;119:281-293.

7. Rohrer B, Fasoli S, Krebs HI, et al. Movement smoothness changes during stroke recovery. J Neurosci. Sep 15 2002;22(18):8297-8304.

8. Lance JW. The control of muscle tone, reflexes, and movement: Robert Wartenberg Lecture. Neurology. Dec 1980;30(12):1303-1313.

9. Mottram CJ, Suresh NL, Heckman CJ, Gorassini MA, Rymer WZ. Origins of abnormal excitability in biceps brachii motoneurons of spastic-paretic stroke survivors. $J$ Neurophysiol. Oct 2009;102(4):2026-2038.

10. Gracies JM. Pathophysiology of spastic paresis. II: Emergence of muscle overactivity. Muscle Nerve. May 2005;31(5):552-571. 
Faster speed for reaching.

11. Brunnstrom S. Movement Therapy in Hemiplegia: A Neurophysiological Approach. New York: Harper \& Row; 1970.

12. DeJong SL, Schaefer SY, Lang CE. Need for speed: better movement quality during faster task performance after stroke. Neurorehabil Neural Repair. May 2012;26(4):362-373.

13. Massie CL, Malcolm MP. Instructions emphasizing speed improves hemiparetic arm kinematics during reaching in stroke. NeuroRehabilitation. 2012;30(4):341-350.

14. Pereira S, Silva CC, Ferreira S, et al. Anticipatory postural adjustments during sitting reach movement in post-stroke subjects. J Electromyogr Kinesiol. Feb 2014;24(1):165-171.

15. van Vliet PM, Sheridan MR. Coordination between reaching and grasping in patients with hemiparesis and healthy subjects. Arch Phys Med Rehabil. Oct 2007;88(10):1325-1331.

16. Gottlieb GL, Corcos DM, Agarwal GC. Organizing principles for single-joint movements. I. A speed-insensitive strategy. J Neurophysiol. Aug 1989;62(2):342-357.

17. Gottlieb GL, Corcos DM, Agarwal GC, Latash ML. Organizing principles for single joint movements. III. Speed-insensitive strategy as a default. J Neurophysiol. Mar $1990 ; 63(3): 625-636$.

18. Ghez C, Gordon J. Trajectory control in targeted force impulses. I. Role of opposing muscles. Exp Brain Res. 1987;67(2):225-240.

19. Gordon J, Ghez C. Trajectory control in targeted force impulses. II. Pulse height control. Exp Brain Res. 1987;67(2):241-252.

20. Mutha PK, Sainburg RL. Control of velocity and position in single joint movements. Hum Mov Sci. Dec 2007;26(6):808-823.

21. Sainburg RL, Schaefer SY. Interlimb differences in control of movement extent. $J$ Neurophysiol. Sep 2004;92(3):1374-1383.

$-21-$ 
Faster speed for reaching.

22. Stewart JC, Gordon J, Winstein CJ. Control of reach extent with the paretic and nonparetic arms after unilateral sensorimotor stroke II: planning and adjustments to control movement distance. Exp Brain Res. Nov 2014;232(11):3431-3443.

23. Powers RK, Campbell DL, Rymer WZ. Stretch reflex dynamics in spastic elbow flexor muscles. Ann Neurol. Jan 1989;25(1):32-42.

24. Jobin A, Levin MF. Regulation of stretch reflex threshold in elbow flexors in children with cerebral palsy: a new measure of spasticity. Dev Med Child Neurol. Aug 2000;42(8):531-540.

25. Bensmail D, Robertson JV, Fermanian C, Roby-Brami A. Botulinum toxin to treat upper-limb spasticity in hemiparetic patients: analysis of function and kinematics of reaching movements. Neurorehabil Neural Repair. Mar-Apr 2010;24(3):273-281.

26. Ibrahim IK, Berger W, Trippel M, Dietz V. Stretch-induced electromyographic activity and torque in spastic elbow muscles. Differential modulation of reflex activity in passive and active motor tasks. Brain. Aug 1993;116 ( Pt 4):971-989.

27. Mackey AH, Miller F, Walt SE, Waugh MC, Stott NS. Use of three-dimensional kinematic analysis following upper limb botulinum toxin A for children with hemiplegia. Eur J Neurol. Nov 2008;15(11):1191-1198.

28. Ohn SH, Yoo WK, Kim DY, et al. Measurement of synergy and spasticity during functional movement of the post-stroke hemiplegic upper limb. J Electromyogr Kinesiol. Apr 2013;23(2):501-507.

29. Reinkensmeyer DJ, Schmit BD, Rymer WZ. Assessment of active and passive restraint during guided reaching after chronic brain injury. Ann Biomed Eng. Nov-Dec 1999;27(6):805-814.

30. Ward AB. A literature review of the pathophysiology and onset of post-stroke spasticity. Eur J Neurol. Jan 2012;19(1):21-27. 
Faster speed for reaching.

31. Musampa NK, Mathieu PA, Levin MF. Relationship between stretch reflex thresholds and voluntary arm muscle activation in patients with spasticity. Exp Brain Res. Aug 2007;181(4):579-593.

32. Cirstea MC, Levin MF. Compensatory strategies for reaching in stroke. Brain. May 2000;123:940-953.

33. Roby-Brami A, Feydy A, Combeaud M, Biryukova EV, Bussel B, Levin MF. Motor compensation and recovery for reaching in stroke patients. Acta Neurol Scand. May 2003;107(5):369-381.

34. Levin MF, Michaelsen SM, Cirstea CM, Roby-Brami A. Use of the trunk for reaching targets placed within and beyond the reach in adult hemiparesis. Exp Brain Res. Mar 2002;143(2):171-180.

35. Roby-Brami A, Fuchs S, Mokhtari M, Bussel B. Reaching and grasping strategies in hemiparetic patients. Motor Control. 1997;1:72-91.

36. Michaelsen SM, Luta A, Roby-Brami A, Levin MF. Effect of trunk restraint on the recovery of reaching movements in hemiparetic patients. Stroke. Aug 2001;32(8):1875-1883. 37. Massie CL, Fritz S, Malcolm MP. Elbow extension predicts motor impairment and performance after stroke. Rehabil Res Pract. 2011;2011:381978.

38. Levin MF, Kleim JA, Wolf SL. What do motor "recovery" and "compensation" mean in patients following stroke? Neurorehabil Neural Repair. May 2009;23(4):313-319.

39. Robertson JV, Roby-Brami A. The trunk as a part of the kinematic chain for reaching movements in healthy subjects and hemiparetic patients. Brain Res. Mar 25 2011;1382:137146.

40. Huang VS, Krakauer JW. Robotic neurorehabilitation: a computational motor learning perspective. J Neuroeng Rehabil. 2009;6:5.

$-23-$ 
Faster speed for reaching.

41. Kitago T, Krakauer JW. Motor learning principles for neurorehabilitation. Handb Clin Neurol. 2013;110:93-103.

42. Nudo RJ. Recovery after brain injury: mechanisms and principles. Front Hum Neurosci. 2013;7:887.

43. Schweighofer N, Choi Y, Winstein C, Gordon J. Task-oriented rehabilitation robotics. Am J Phys Med Rehabil. Nov 2012;91(11 Suppl 3):S270-279.

44. Winstein CJ, Stewart JC. Conditions of task practice for individuals with neurologic impairments. . In: Selzer ME, Clarke S, Cohen LG, Duncan P, Gage F, eds. Textbook of Neural Repair and Rehabilitation. Vol. 2. . Vol 2. Cambridge: Cambridge University Press; 2006:89-102.

45. Elia AE, Filippini G, Calandrella D, Albanese A. Botulinum neurotoxins for poststroke spasticity in adults: a systematic review. Mov Disord. Apr 30 2009;24(6):801-812. 46. Gladstone DJ, Danells CJ, Black SE. The Fugl-Meyer assessment of motor recovery after stroke: a critical review of its measurement properties. Neurorehabil Neural Repair. Sep 2002;16(3):232-240.

47. Platz T, Pinkowski C, van Wijck F, Kim IH, di Bella P, Johnson G. Reliability and validity of arm function assessment with standardized guidelines for the Fugl-Meyer Test, Action Research Arm Test and Box and Block Test: a multicentre study. Clin Rehabil. Jun 2005;19(4):404-411.

48. van der Lee JH, Beckerman H, Knol DL, de Vet HC, Bouter LM. Clinimetric properties of the motor activity log for the assessment of arm use in hemiparetic patients. Stroke. Jun 2004;35(6):1410-1414.

49. Cirstea MC, Mitnitski AB, Feldman AG, Levin MF. Interjoint coordination dynamics during reaching in stroke. Exp Brain Res. Aug 2003;151(3):289-300. $-24-$ 
Faster speed for reaching.

50. Gordon J, Ghilardi MF, Ghez C. Accuracy of planar reaching movements I. Independence of direction and extent variability. Experimental Brain Research. 1994;99:97111.

51. Corcos DM, Gottlieb GL, Agarwal GC. Organizing principles for single-joint movements. II. A speed-sensitive strategy. J Neurophysiol. Aug 1989;62(2):358-368.

52. Stewart JC, Gordon J, Winstein CJ. Control of reach extent with the paretic and nonparetic arms after unilateral sensorimotor stroke: kinematic differences based on side of brain damage. Exp Brain Res. Apr 102014.

53. Hogan N, Sternad D. Sensitivity of smoothness measures to movement duration, amplitude, and arrests. J Mot Behav. Nov 2009;41(6):529-534.

54. Bernstein N. The co-ordination and regulation of movements. Oxford: Pergamon; 1967.

55. Bouisset $\mathrm{S}$, Lestienne $\mathrm{F}$. The organisation of a simple voluntary movement as analysed from its kinematic properties. Brain Res. May 17 1974;71(2-3):451-457.

56. Brown SH, Cooke JD. Amplitude- and instruction-dependent modulation of movement-related electromyogram activity in humans. J Physiol. Jul 1981;316:97-107.

57. Atkeson CG, Hollerbach JM. Kinematic features of unrestrained vertical arm movements. The Journal of Neuroscience. 1985;5:2318-2330.

58. Nishikawa KC, Murray ST, Flanders M. Do arm postures vary with the speed of reaching? J Neurophysiol. May 1999;81(5):2582-2586.

59. Soechting JF, Lacquaniti F. Invariant characteristics of a pointing movement in man. $J$ Neurosci. Jul 1981;1(7):710-720.

60. Torres EB, Zipser D. Simultaneous control of hand displacements and rotations in orientation-matching experiments. J Appl Physiol. May 2004;96(5):1978-1987.

$-25-$ 
Faster speed for reaching.

61. Scholz JP, Dwight-Higgin T, Lynch JE, Tseng YW, Martin V, Schoner G. Motor equivalence and self-motion induced by different movement speeds. Exp Brain Res. Mar 2011;209(3):319-332.

62. Adamovich SV, Levin MF, Feldman AG. Central modifications of reflex parameters may underlie the fastest arm movements. J Neurophysiol. Mar 1997;77(3):1460-1469.

63. Feldman AG, Adamovich SV, Levin MF. The relationship between control, kinematic and electromyographic variables in fast single-joint movements in humans. Exp Brain Res. $1995 ; 103(3): 440-450$.

64. Lacquaniti F, Soechting JF. Coordination of arm and wrist motion during a reaching task. J Neurosci. Apr 1982;2(4):399-408.

65. Lindberg PG, Gaverth J, Islam M, Fagergren A, Borg J, Forssberg H. Validation of a new biomechanical model to measure muscle tone in spastic muscles. Neurorehabil Neural Repair. Sep 2011;25(7):617-625.

66. Vinti M, Couillandre A, Hausselle J, et al. Influence of effort intensity and gastrocnemius stretch on co-contraction and torque production in the healthy and paretic ankle. Clin Neurophysiol. Mar 2013;124(3):528-535.

67. Ada L, Canning CG, Carr JH, Kilbreath SL, Shepherd RB. Task specific training of reaching and manipulation. In: Bennett $\mathrm{K}$, Castiello U, eds. Insights into the reach to grasp movement: Elsevier; 1994.

68. Hidaka Y, Han CE, Wolf SL, Winstein CJ, Schweighofer N. Use it and improve it or lose it: interactions between arm function and use in humans post-stroke. PLoS Comput Biol. Feb 2012;8(2):e1002343.

69. Taub E, Uswatte G, Mark VW, Morris DM. The learned nonuse phenomenon: implications for rehabilitation. Eura Medicophys. Sep 2006;42(3):241-256.

$-26-$ 
Faster speed for reaching.

70. Pain LM, Baker R, Richardson D, Agur AM. Effect of trunk-restraint training on function and compensatory trunk, shoulder and elbow patterns during post-stroke reach: a systematic review. Disabil Rehabil. Jun 25 2014:1-10.

71. Wee SK, Hughes AM, Warner M, Burridge JH. Trunk Restraint to Promote Upper Extremity Recovery in Stroke Patients: A Systematic Review and Meta-Analysis.

Neurorehabil Neural Repair. Feb 10 2014;28(7):660-677.

$-27-$ 
Faster speed for reaching.

\section{Figure legends}

Figure 1: Effect of speed condition on hand kinematics.

A: Reach distance. B: Maximum peak velocity, C: Reach duration, D: Peak count. The effect of target distance (close, far) and trunk condition (free, restraint) are represented on the abscissa of each panel. Open circles indicate the preferred speed condition and black circles the fast speed condition. Each point represents the mean of the 14 subjects. The standard error of the mean is indicated. The asterisks indicate the level of statistical significance with a Wilcoxon paired test, for the effect of Target distance, speed condition and trunk restraint. **: $\mathrm{p}<0.006 ; * * * \mathrm{p}<=0.001$

Figure 2: Effect of speed condition on elbow extension and trunk displacement.

Displacement of the sensor fixed on the sternum (A) and on the acromion (B). Elbow extension amplitude (C) and elbow extension velocity (D). Same legend as Figure 1.

Figure 3. Scaling of elbow extension in individual patients.

Effect of reach distance on elbow extension in the trunk free (A) and trunk fixed (B) conditions. Each line indicates the regression of the 6-10 samples recorded for one patient and in one experimental condition. The extremities of each line relate to the shortest and longest reach distances observed within these trials. Full lines indicate significant regressions and dotted lines non-significant regressions. The stippled line represents zero extension. Grey lines indicate the preferred speed condition and black lines the fast speed.

C: Effect of speed condition (preferred in grey and fast in black) on elbow extension amplitude (upper part) and velocity (lower part) for the close and far targets in the trunk free and restrained conditions. The patients are ranked according to their ability to scale elbow 
Faster speed for reaching.

extension to movement distance (the regressions of elbow extension to movement distance were significant for the first 7 patients, whatever the condition).

Figure 4. Contribution of trunk displacement and upper-limb lengthening to reach distance in individual patients.

Influence of the speed condition on the relative contributions of trunk displacement and upper-limb lengthening (trunk free condition). Each vector represents one subject and joins values for the preferred and fast speed conditions. Close targets are represented in grey and far in black. The dotted lines indicate patients who did not scale elbow extension as a function of reach distance.

$-29-$ 
Faster speed for reaching.

Table 1: Patients characteristics.

\begin{tabular}{|c|c|c|c|c|c|c|}
\hline ID & Age & $\begin{array}{c}\text { Gen- } \\
\text { der }\end{array}$ & $\begin{array}{l}\text { Time } \\
\text { since } \\
\text { stroke } \\
\text { (years) }\end{array}$ & Side & Type & Location \\
\hline 1 & 47 & $\mathrm{~F}$ & 5 & $\mathrm{~L}$ & Hem & Supp. MCA2 \\
\hline 2 & 39 & $\mathrm{~F}$ & 2 & $\mathrm{R}$ & Isch & MCA \\
\hline 3 & 54 & $M$ & 1 & $\mathrm{R}$ & Isch & Deep MCA \\
\hline 4 & 60 & $M$ & 18 & $\mathrm{R}$ & Isch & MCA \\
\hline 5 & 54 & $\mathrm{~F}$ & 5 & $\mathrm{R}$ & Isch & MCA \\
\hline 6 & 42 & $M$ & 6 & $\mathrm{~L}$ & Isch & MCA \\
\hline 7 & 43 & $M$ & 6 & L & Isch & MCA \\
\hline 8 & 59 & $\mathrm{M}$ & 7 & $\mathrm{R}$ & Isch & MCA \\
\hline 9 & 74 & $M$ & 6 & L & Hem & Deep MCA \\
\hline 10 & 65 & $\mathrm{~F}$ & 7 & $R$ & Isch & Deep MCA \\
\hline 11 & 55 & $\mathrm{~F}$ & 6 & L & Hem & capsular \\
\hline 12 & 47 & $\mathrm{M}$ & 1 & $\mathrm{R}$ & Isch & MCA \\
\hline 13 & 32 & $\mathrm{~F}$ & 7 & $\mathrm{R}$ & Hem & thalamic \\
\hline 14 & 55 & $M$ & 12 & L & Isch & MCA \\
\hline
\end{tabular}

MCA: medial cerebral artery, supp: superficial.

Hem: hemorrhagic

Isch: ischemic

$-30-$ 
Faster speed for reaching.

Table 2:Clinical assessment of the patients.

\begin{tabular}{|c|c|c|c|c|c|c|c|c|c|}
\hline & \multicolumn{5}{|c|}{ Fugl Meyer } & & & & \\
\cline { 2 - 8 } & UL & Sh-el & wrist & hand & ARAT & MAL1 & MAL2 & Barthel & Ashworth \\
\hline 1 & 42 & 26 & 8 & 5 & 8 & 42 & 31 & 95 & 1.5 \\
\hline 2 & 52 & 29 & 6 & 13 & 56 & 47 & 52 & 100 & 1.5 \\
\hline 3 & 31 & 15 & 4 & 8 & 3 & 17 & 17 & 100 & 1.5 \\
\hline 4 & 53 & 29 & 9 & 11 & 54 & 109 & 105 & 100 & 1.5 \\
\hline 5 & 32 & 21 & 4 & 5 & 15 & 21 & 16 & 95 & 1 \\
\hline 6 & 37 & 24 & 1 & 6 & 21 & 10 & 10 & 100 & 1.5 \\
\hline 7 & 25 & 17 & 2 & 4 & 14 & 1 & 1 & 95 & 1.5 \\
\hline 8 & 26 & 20 & 1 & 4 & 4 & 6 & 6 & 90 & 1 \\
\hline 9 & 43 & 24 & 6 & 9 & 12 & 18 & 19 & 95 & 3 \\
\hline 10 & 31 & 20 & 2 & 6 & 32 & 17 & 20 & 95 & 1.5 \\
\hline 11 & 24 & 16 & 0 & 5 & 6 & 6 & 5 & 90 & 1.5 \\
\hline 12 & 11 & 10 & 0 & 1 & 0 & 2 & 3 & 95 & 3 \\
\hline 13 & 32 & 21 & 3 & 4 & 12 & 14 & 21 & 100 & 1.5 \\
\hline 14 & 39 & 23 & 6 & 5 & 17 & 20 & 19 & 100 & 3 \\
\hline
\end{tabular}

Fugl-Meyer: upper-limb section (UL) and subsections (Sh-El: shoulder-elbow, wrist and hand).

ARAT : Action research arm test.

MAL 1: Motor activity log, amount of use

MAL 2: Motor activity log, quality of movement

Patients are ranked according to their ability to scale elbow extension as a function of target distance. For patients 1-7, the regression lines were significant in all the speed and trunk conditions (they are ranked according to the slope of the regression line in the fast speed, trunk fixed condition). For patients 8-9 the regressions were significant except in the trunk free/preferred speed condition. For the other patients (10-14), the regression lines were mostly non significant (they are ranked according to the degree of elbow extension).

$-31-$ 

A. Reach distance. B: Maximum peak velocity, C: Reach duration, D: Peak count. The effect of target
distance (close, far) and trunk condition (free, restraint) are represented on the abscissa of each panel. Open circles indicate the preferred speed condition and black circles the fast speed condition. Each point represents the mean of the 14 subjects. The standard error of the mean is indicated. The asterisks indicate the level of statistical significance with a Wilcoxon paired test, for the effect of Target distance, speed condition and trunk restraint. $* *: p<0.006 ; * * * p<=0.001$.

$114 \times 84 \mathrm{~mm}(300 \times 300$ DPI $)$ 

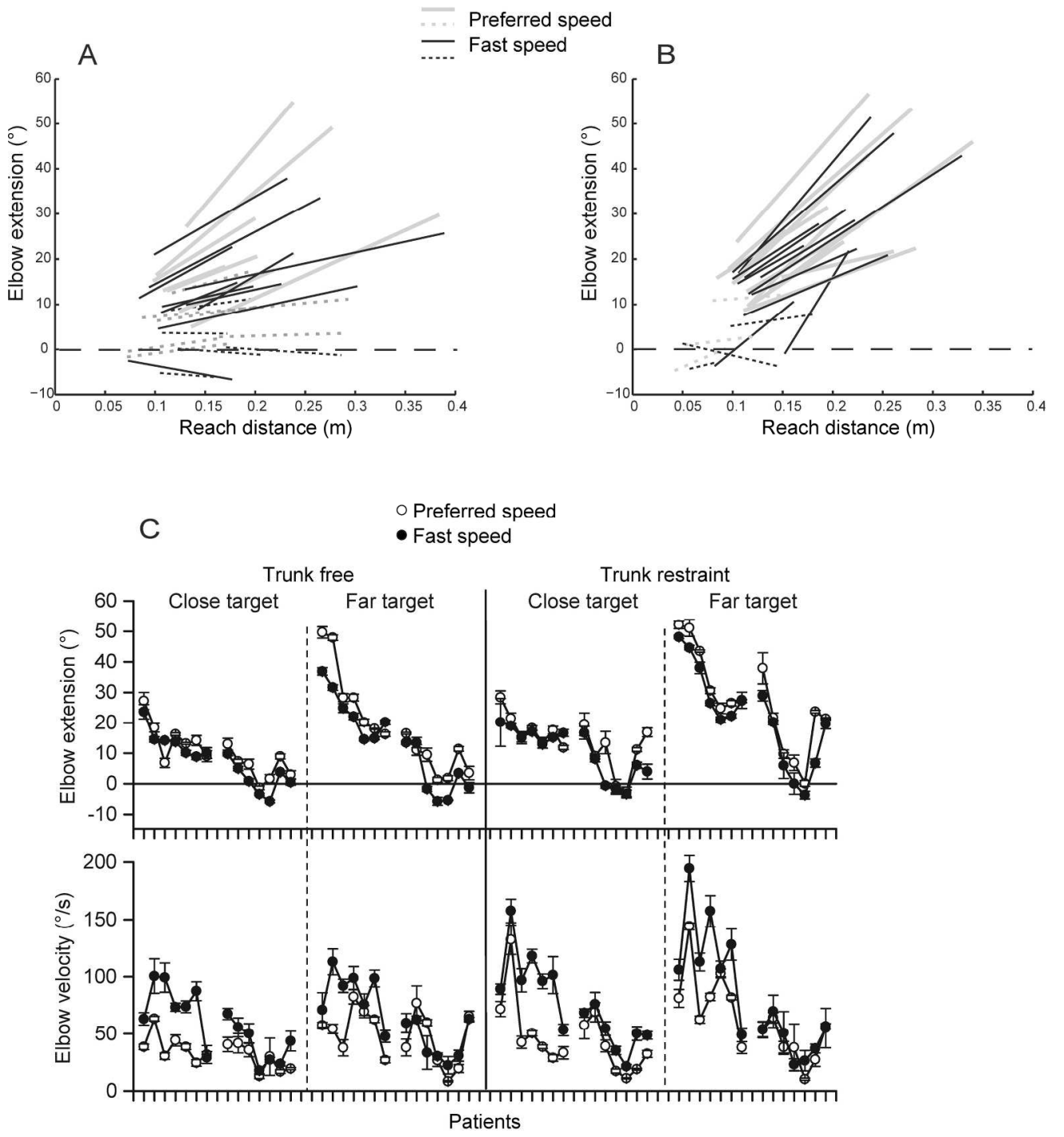

Figure 3. Scaling of elbow extension in individual patients.

Effect of reach distance on elbow extension in the trunk free (A) and trunk fixed (B) conditions. Each line indicates the regression of the 6-10 samples recorded for one patient and in one experimental condition. The extremities of each line relate to the shortest and longest reach distances observed within these trials.

Full lines indicate significant regressions and dotted lines non-significant regressions. The stippled line represents zero extension. Grey lines indicate the preferred speed condition and black lines the fast speed. C: Effect of speed condition (preferred in grey and fast in black) on elbow extension amplitude (upper part) and velocity (lower part) for the close and far targets in the trunk free and restrained conditions. The patients are ranked according to their ability to scale elbow extension to movement distance (the regressions of elbow extension to movement distance were significant for the first 7 patients, whatever the condition). 


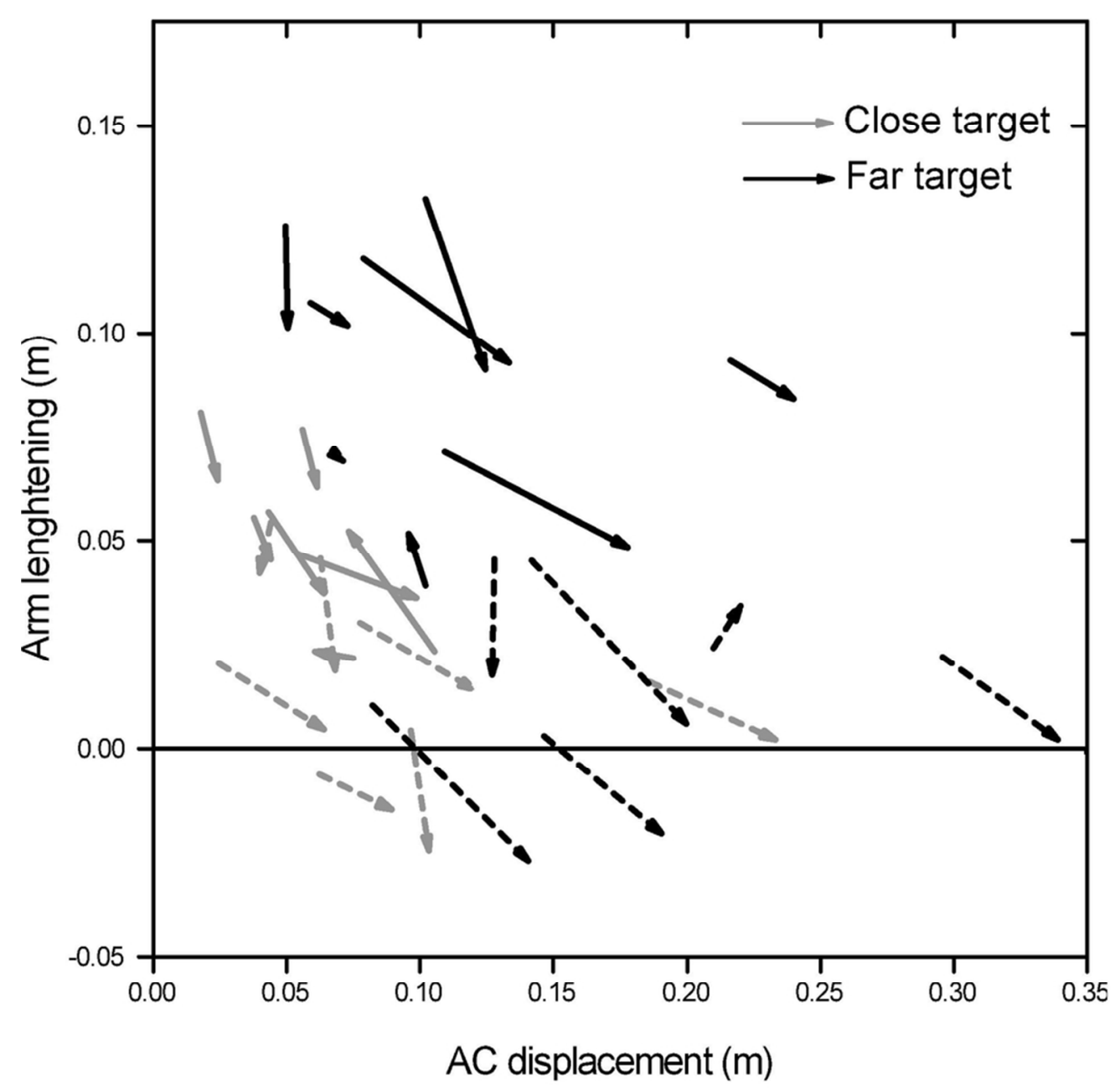

Figure 4. Contribution of trunk displacement and upper-limb lengthening to reach distance in individual patients.

Influence of the speed condition on the relative contributions of trunk displacement and upper-limb lengthening (trunk free condition). Each vector represents one subject and joins values for the preferred and fast speed conditions. Close targets are represented in grey and far in black. The dotted lines indicate patients who did not scale elbow extension as a function of reach distance.

$80 \times 78 \mathrm{~mm}(300 \times 300 \mathrm{DPI})$ 
Faster speed for reaching.

Table 1: Patients characteristics.

\begin{tabular}{|c|c|c|c|c|c|c|}
\hline ID & Age & $\begin{array}{c}\text { Gen- } \\
\text { der }\end{array}$ & $\begin{array}{c}\text { Time } \\
\text { since } \\
\text { stroke } \\
\text { (years) }\end{array}$ & Side & Type & Location \\
\hline 1 & 47 & $\mathrm{~F}$ & 5 & L & Hem & Supp. MCA2 \\
\hline 2 & 39 & $\mathrm{~F}$ & 2 & $\mathrm{R}$ & Isch & MCA \\
\hline 3 & 54 & $\mathrm{M}$ & 1 & $\mathrm{R}$ & Isch & Deep MCA \\
\hline 4 & 60 & $\mathrm{M}$ & 18 & $\mathrm{R}$ & Isch & MCA \\
\hline 5 & 54 & $\mathrm{~F}$ & 5 & $\mathrm{R}$ & Isch & MCA \\
\hline 6 & 42 & $\mathrm{M}$ & 6 & $\mathrm{~L}$ & Isch & MCA \\
\hline 7 & 43 & $\mathrm{M}$ & 6 & $\mathrm{~L}$ & Isch & MCA \\
\hline 8 & 59 & $\mathrm{M}$ & 7 & $\mathrm{R}$ & Isch & MCA \\
\hline 9 & 74 & $\mathrm{M}$ & 6 & $\mathrm{~L}$ & Hem & Deep MCA \\
\hline 10 & 65 & $\mathrm{~F}$ & 7 & $\mathrm{R}$ & Isch & Deep MCA \\
\hline 11 & 55 & $\mathrm{~F}$ & 6 & $\mathrm{~L}$ & Hem & capsular \\
\hline 12 & 47 & $\mathrm{M}$ & 1 & $\mathrm{R}$ & Isch & MCA \\
\hline 13 & 32 & $\mathrm{~F}$ & 7 & $\mathrm{R}$ & Hem & thalamic \\
\hline 14 & 55 & $\mathrm{M}$ & 12 & $\mathrm{~L}$ & Isch & MCA \\
\hline
\end{tabular}

MCA: medial cerebral artery, supp: superficial.

Hem: hemorrhagic

Isch: ischemic

$-1-$ 
Faster speed for reaching.

Table 2:Clinical assessment of the patients.

\begin{tabular}{|c|c|c|c|c|c|c|c|c|c|}
\hline & \multicolumn{5}{|c|}{ Fugl Meyer } & \multirow{2}{*}{} & & & \\
\cline { 2 - 9 } & UL & Sh-el & wrist & hand & ARAT & MAL1 & MAL2 & Barthel & Ashworth \\
\hline 1 & 42 & 26 & 8 & 5 & 8 & 42 & 31 & 95 & 1.5 \\
\hline 2 & 52 & 29 & 6 & 13 & 56 & 47 & 52 & 100 & 1.5 \\
\hline 3 & 31 & 15 & 4 & 8 & 3 & 17 & 17 & 100 & 1.5 \\
\hline 4 & 53 & 29 & 9 & 11 & 54 & 109 & 105 & 100 & 1.5 \\
\hline 5 & 32 & 21 & 4 & 5 & 15 & 21 & 16 & 95 & 1 \\
\hline 6 & 37 & 24 & 1 & 6 & 21 & 10 & 10 & 100 & 1.5 \\
\hline 7 & 25 & 17 & 2 & 4 & 14 & 1 & 1 & 95 & 1.5 \\
\hline 8 & 26 & 20 & 1 & 4 & 4 & 6 & 6 & 90 & 1 \\
\hline 9 & 43 & 24 & 6 & 9 & 12 & 18 & 19 & 95 & 3 \\
\hline 10 & 31 & 20 & 2 & 6 & 32 & 17 & 20 & 95 & 1.5 \\
\hline 11 & 24 & 16 & 0 & 5 & 6 & 6 & 5 & 90 & 1.5 \\
\hline 12 & 11 & 10 & 0 & 1 & 0 & 2 & 3 & 95 & 3 \\
\hline 13 & 32 & 21 & 3 & 4 & 12 & 14 & 21 & 100 & 1.5 \\
\hline 14 & 39 & 23 & 6 & 5 & 17 & 20 & 19 & 100 & 3 \\
\hline
\end{tabular}

Fugl-Meyer: upper-limb section (UL) and subsections (Sh-El: shoulder-elbow, wrist and hand).

ARAT : Action research arm test.

MAL 1: Motor activity log, amount of use

MAL 2: Motor activity log, quality of movement

Patients are ranked according to their ability to scale elbow extension as a function of target

distance. For patients 1-7, the regression lines were significant in all the speed and trunk

conditions (they are ranked according to the slope of the regression line in the fast speed,

trunk fixed condition). For patients 8-9 the regressions were significant except in the trunk

free/preferred speed condition. For the other patients (10-14), the regression lines were mostly

non significant (they are ranked according to the degree of elbow extension).

$-31-$ 
Faster speed at the expense of movement coordination in chronic spastic stroke patients. Supplementary material.

\section{Table S1:}

Individual results of peak velocity $(\mathrm{m} / \mathrm{s})$.

The patients are ranked as in Table 1 and 2.

\begin{tabular}{|c|l|l|l|l|l|l|l|l|}
\hline & \multicolumn{4}{|c|}{ Trunk free } & \multicolumn{2}{c|}{ Prunk restrained } \\
\hline & \multicolumn{2}{|c|}{ Preferred } & Fast & Prefred & \multicolumn{2}{c|}{ Fast } \\
\hline ID & Close & Far & Close & Far & Close & Far & Close & Far \\
\hline 1 & $0.23 \pm 0.02$ & $0.44 \pm 0.04$ & $0.39 \pm 0.04$ & $0.68 \pm 0.05$ & $0.33 \pm 0.03$ & $0.53 \pm 0.06$ & $0.40 \pm 0.03$ & $0.67 \pm 0.04$ \\
\hline 2 & $0.29 \pm 0.01$ & $0.48 \pm 0.02$ & $0.65 \pm 0.01$ & $0.82 \pm 0.03$ & $0.33 \pm 0.04$ & $0.50 \pm 0.02$ & $0.71 \pm 0.02$ & $0.81 \pm 0.01$ \\
\hline 3 & $0.30 \pm 0.02$ & $0.88 \pm 0.07$ & $0.44 \pm 0.02$ & $0.84 \pm 0.06$ & $0.36 \pm 0.01$ & $0.59 \pm 0.03$ & $0.57 \pm 0.02$ & $0.83 \pm 0.02$ \\
\hline 4 & $0.27 \pm 0.02$ & $0.45 \pm 0.02$ & $0.35 \pm 0.02$ & $0.71 \pm 0.02$ & $0.45 \pm 0.02$ & $0.62 \pm 0.03$ & $0.52 \pm 0.01$ & $0.83 \pm 0.05$ \\
\hline 5 & $0.28 \pm 0.01$ & $0.55 \pm 0.03$ & $0.37 \pm 0.01$ & $0.69 \pm 0.04$ & $0.34 \pm 0.04$ & $0.54 \pm 0.08$ & $0.51 \pm 0.02$ & $0.99 \pm 0.04$ \\
\hline 6 & $0.26 \pm 0.03$ & $0.64 \pm 0.10$ & $0.25 \pm 0.01$ & $0.73 \pm 0.08$ & $0.36 \pm 0.01$ & $0.60 \pm 0.01$ & $0.44 \pm 0.02$ & $0.74 \pm 0.06$ \\
\hline 7 & $0.26 \pm 0.03$ & $0.38 \pm 0.03$ & $0.29 \pm 0.05$ & $0.49 \pm 0.03$ & $0.34 \pm 0.03$ & $0.38 \pm 0.02$ & $0.35 \pm 0.02$ & $0.36 \pm 0.02$ \\
\hline 8 & $0.34 \pm 0.03$ & $0.54 \pm 0.03$ & $0.57 \pm 0.02$ & $0.68 \pm 0.07$ & $0.27 \pm 0.03$ & $0.41 \pm 0.02$ & $0.31 \pm 0.02$ & $0.41 \pm 0.06$ \\
\hline 9 & $0.34 \pm 0.03$ & $0.50 \pm 0.05$ & $0.44 \pm 0.04$ & $0.87 \pm 0.05$ & $0.44 \pm 0.06$ & $0.57 \pm 0.04$ & $0.52 \pm 0.07$ & $0.72 \pm 0.07$ \\
\hline 10 & $0.32 \pm 0.05$ & $0.53 \pm 0.02$ & $0.45 \pm 0.02$ & $0.65 \pm 0.01$ & $0.34 \pm 0.03$ & $0.28 \pm 0.05$ & $0.25 \pm 0.03$ & $0.45 \pm 0.08$ \\
\hline 11 & $0.16 \pm 0.02$ & $0.26 \pm 0.03$ & $0.20 \pm 0.03$ & $0.46 \pm 0.05$ & $0.22 \pm 0.04$ & $0.31 \pm 0.04$ & $0.20 \pm 0.02$ & $0.30 \pm 0.05$ \\
\hline 12 & $0.28 \pm 0.16$ & $0.51 \pm 0.05$ & $0.12 \pm 0.01$ & $0.46 \pm 0.06$ & $0.20 \pm 0.02$ & $0.41 \pm 0.06$ & $0.15 \pm 0.02$ & $0.40 \pm 0.13$ \\
\hline 13 & $0.16 \pm 0.02$ & $0.35 \pm 0.03$ & $0.24 \pm 0.01$ & $0.49 \pm 0.01$ & $0.14 \pm 0.01$ & $0.38 \pm 0.03$ & $0.14 \pm 0.00$ & $0.47 \pm 0.06$ \\
\hline 14 & $0.43 \pm 0.03$ & $0.84 \pm 0.05$ & $0.58 \pm 0.03$ & $0.98 \pm 0.06$ & $0.56 \pm 0.03$ & $0.72 \pm 0.03$ & $0.59 \pm 0.02$ & $0.69 \pm 0.07$ \\
\hline
\end{tabular}




\section{Table S2: Scaling of elbow rotation as a function of movement distance.}

$$
\text { Results of the regression analysis: slope, and ordinate at the origin (b) of the regression line and }
$$
regression coefficient; a non significant regression is indicated by grey text. Red text indicates elbow flexion.

\begin{tabular}{|c|c|c|c|c|c|c|}
\hline & \multicolumn{6}{|c|}{ Trunk free } \\
\cline { 2 - 8 } & \multicolumn{3}{|c|}{ Preferred } & & \multicolumn{3}{c|}{ Fast } \\
\hline ID & $\mathrm{b}$ & slope & $\mathrm{r} 2$ & $\mathrm{~b}$ & slope & $\mathrm{r} 2$ \\
\hline 1 & -6.89 & 259.44 & 0.83 & 8.42 & 126.89 & 0.89 \\
\hline 2 & -2.36 & 186.03 & 1.00 & 2.98 & 115.20 & 0.98 \\
\hline 3 & 1.87 & 135.60 & 0.93 & 1.30 & 120.59 & 0.92 \\
\hline 4 & -8.59 & 99.92 & 0.93 & 7.16 & 47.60 & 0.85 \\
\hline 5 & -3.63 & 97.02 & 0.65 & -9.67 & 130.05 & 0.75 \\
\hline 6 & 3.86 & 85.40 & 0.74 & -1.08 & 87.46 & 0.86 \\
\hline 7 & 3.66 & 83.89 & 0.85 & 3.61 & 48.26 & 0.82 \\
\hline 8 & 5.43 & 60.81 & 0.51 & 4.28 & 49.11 & 0.80 \\
\hline 9 & 5.32 & 20.00 & 0.40 & -0.25 & 47.25 & 0.73 \\
\hline 10 & 3.25 & 30.80 & 0.16 & 2.20 & -16.54 & 0.11 \\
\hline 11 & -3.74 & 28.65 & 0.40 & 0.38 & -39.82 & 0.51 \\
\hline 12 & -2.71 & 31.24 & 0.40 & -3.45 & -16.79 & 0.17 \\
\hline 13 & 5.14 & 31.09 & 0.33 & 3.97 & -2.75 & 0.01 \\
\hline 14 & 1.75 & 6.32 & 0.02 & 2.99 & -14.96 & 0.22 \\
\hline
\end{tabular}

\begin{tabular}{|c|c|c|c|c|c|c|}
\hline & \multicolumn{7}{|c|}{ Trunk restrained } \\
\hline & \multicolumn{3}{|c|}{ Preferred } & & \multicolumn{3}{c|}{ Fast } \\
\hline ID & $\mathrm{b}$ & slope & $\mathrm{r} 2$ & $\mathrm{~b}$ & slope & $\mathrm{r} 2$ \\
\hline 1 & -2.21 & 249.56 & 0.98 & -10.70 & 261.11 & 0.61 \\
\hline 2 & -0.76 & 193.88 & 0.97 & -1.98 & 190.99 & 0.99 \\
\hline 3 & 4.00 & 140.77 & 0.96 & 1.55 & 140.93 & 0.94 \\
\hline 4 & -9.13 & 162.17 & 0.95 & -4.23 & 143.25 & 0.97 \\
\hline 5 & -15.90 & 221.52 & 0.62 & -1.11 & 133.61 & 0.74 \\
\hline 6 & -7.60 & 225.27 & 0.91 & 1.44 & 125.58 & 0.98 \\
\hline 7 & -1.77 & 128.48 & 0.91 & 0.86 & 95.44 & 0.92 \\
\hline 8 & -6.45 & 210.16 & 0.89 & -0.65 & 148.09 & 0.86 \\
\hline 9 & -0.23 & 79.83 & 0.89 & -2.66 & 92.26 & 0.92 \\
\hline 10 & 9.45 & 17.65 & 0.01 & -18.55 & 181.17 & 0.72 \\
\hline 11 & -0.51 & 27.66 & 0.01 & 3.93 & -52.79 & 0.12 \\
\hline 12 & -8.72 & 95.68 & 0.69 & -7.39 & 53.99 & 0.12 \\
\hline 13 & -7.81 & 150.00 & 0.99 & 2.06 & 31.66 & 0.20 \\
\hline 14 & 8.49 & 50.53 & 0.82 & -54.96 & 355.33 & 0.92 \\
\hline
\end{tabular}


Table S3 Scaling of AA displacement as a function of movement distance, trunk free.

Results of the regression analysis: slope, and ordinate at the origin (b) of the regression line and regression coefficient. Red text indicates slopes $\geq 1$, meaning that the displacement of the hand is due only to trunk displacement, in the patients who do not extend the elbow significantly (or even flex) during reaching.

\begin{tabular}{|r|c|c|c|c|c|c|}
\hline & \multicolumn{5}{|c|}{ Trunk free } \\
\hline & \multicolumn{3}{|c|}{ Preferred } & \multicolumn{3}{c|}{ Fast } \\
\hline & B & slope & r2 & $\mathrm{b}$ & slope & $\mathrm{r} 2$ \\
\hline ID & 0.02 & 0.28 & 0.42 & -0.01 & 0.65 & 0.94 \\
\hline 1 & -0.01 & 0.40 & 0.96 & -0.01 & 0.55 & 0.99 \\
\hline 2 & -0.02 & 0.36 & 0.74 & -0.01 & 0.36 & 0.82 \\
\hline 3 & 0.02 & 0.53 & 0.96 & -0.04 & 0.76 & 0.98 \\
\hline 4 & 0.02 & 0.39 & 0.55 & -0.01 & 0.46 & 0.52 \\
\hline 5 & 0.00 & 0.34 & 0.82 & 0.05 & 0.15 & 0.41 \\
\hline 6 & -0.03 & 0.70 & 0.96 & -0.02 & 0.88 & 0.97 \\
\hline 7 & -0.01 & 0.41 & 0.63 & -0.01 & 0.46 & 0.89 \\
\hline 8 & -0.07 & 0.99 & 0.98 & -0.03 & 0.86 & 0.98 \\
\hline 9 & -0.01 & 0.82 & 0.93 & -0.04 & 1.23 & 0.94 \\
\hline 10 & -0.03 & 1.08 & 0.93 & -0.04 & 1.40 & 0.91 \\
\hline 11 & 0.01 & 0.63 & 0.67 & -0.01 & 1.01 & 0.89 \\
\hline 12 & -0.05 & 0.89 & 0.91 & -0.05 & 1.10 & 0.95 \\
\hline 13 & 0.03 & 0.94 & 0.95 & 0.07 & 0.97 & 0.95 \\
\hline
\end{tabular}


Supplementary Figure S1.

Scaling of acromion displacement in individual patients.

Effect of reach distance on acromion displacement in the trunk free (A) and trunk fixed (B) conditions. Each line indicates the regression of the 6-10 samples recorded for one patient and in one experimental condition. The extremities of each line relate to the shortest and longest reach distances observed within these trials. Full lines indicate significant regressions and dotted lines non-significant regressions. Grey lines indicate the preferred speed condition and black lines the fast speed.
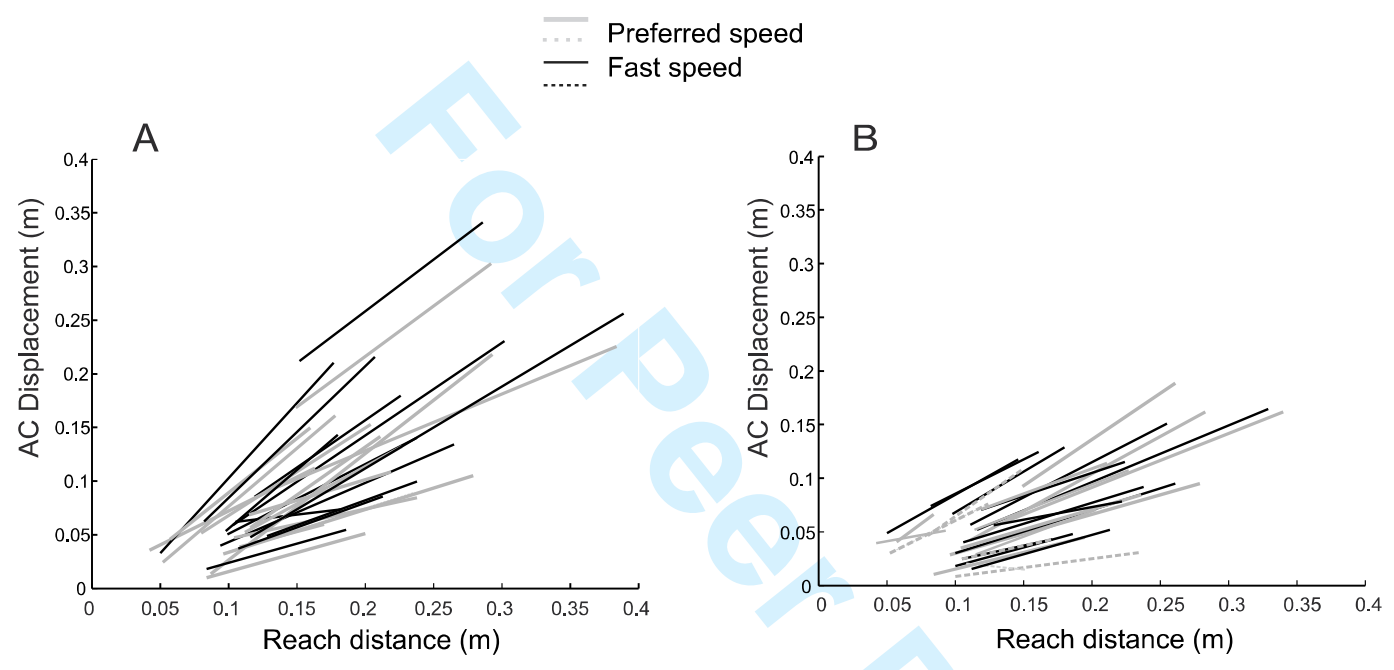
Supplementary Figure S2.

Sum of AC displacement and upper-limb lengthening as a function of reach distance in the different conditions. Each point represents the mean in one condition in one patient. The bisecting line indicates equality. The significant regression with a slope $1(\mathrm{r} 2=0.85$, slope 0.98$)$ shows that the sum of trunk and upper-limb contributions is a good approximation of reach distance.

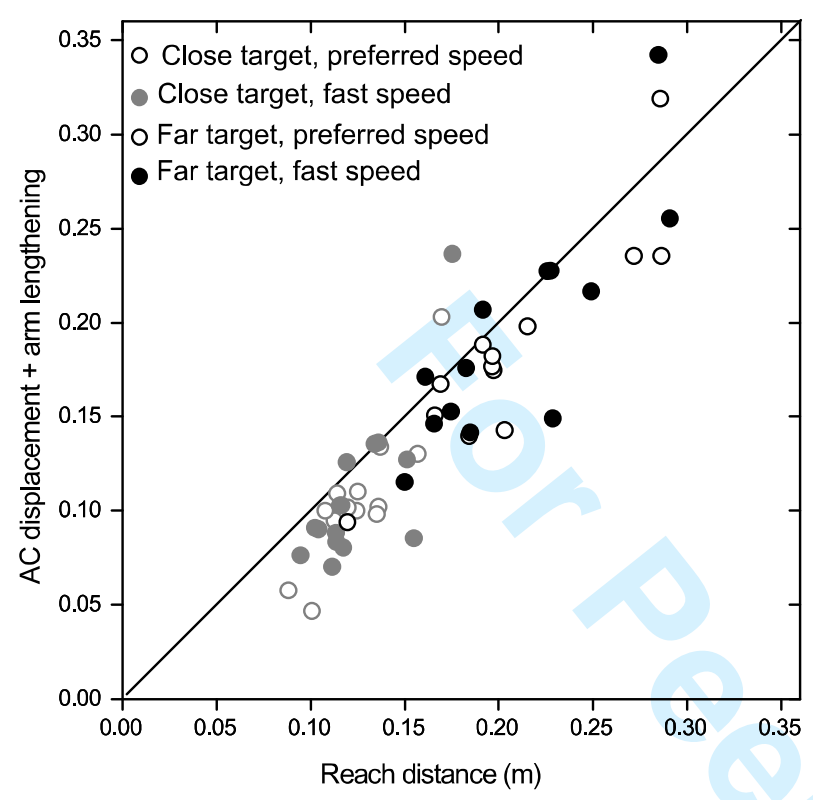

